\title{
Production and characterization of monoclonal antibodies to outer membrane proteins of Pseudomonas aeruginosa grown in iron-depleted media
}

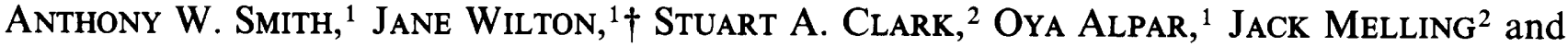 \\ Michael R. W. BROWN ${ }^{1 *}$ \\ ${ }^{1}$ Microbiology Research Group, Pharmaceutical Sciences Institute, Aston University, Aston Triangle, \\ Birmingham B4 7ET, UK \\ ${ }^{2}$ Biologics Division, Public Health Laboratory Service, Centre for Applied Microbiology and Research, Porton Down, \\ Salisbury, Wiltshire SP4 OJG, UK
}

(Received 6 August 1990; revised 18 September 1990; accepted 1 October 1990)

\begin{abstract}
The iron uptake systems of pathogenic bacteria provide potential targets for immunological intervention. We have partially purified the high molecular mass, iron-regulated outer membrane proteins (IROMPs) from Pseudomonas aeruginosa and used them to prepare a panel of monoclonal antibodies (mAbs). Five mAbs reacted with an $85 \mathrm{kDa}$ IROMP separated by SDS-PAGE, but gave only low-level binding to whole cells by immunogold electron microscopy. However, iodination of whole cells indicated that the $85 \mathrm{kDa}$ IROMP is surface-exposed. The mAbs were only cross-reactive with clinical isolates representing eight of the 17 International Antigenic Typing Scheme serotypes of $P$. aeruginosa, suggesting significant heterogeneity with respect to this IROMP.
\end{abstract}

\section{Introduction}

It is widely recognised that the ability of an invading bacterium to adapt rapidly to the host environment is a key determinant of virulence and pathogenicity (Smith, 1990). Although there are a large number of environmental signals, the low availability of iron is acknowledged as a key determinant of virulence (Griffiths, 1987). Iron is predominantly located within the body intracellularly, as haem, haemosiderin and ferritin-type compounds; such extracellular iron is bound to the high-affinity ironbinding glycoproteins transferrin and lactoferrin. In the absence of specific uptake systems the level of free iron is too low to sustain bacterial growth. To obtain iron, many bacterial species secrete low molecular mass iron chelating compounds (siderophores) which compete successfully with transferrin and lactoferrin for iron. Other essential components of the iron acquisition

†Present address: Center for Biotechnology, Karolinska Institute, Novum, Huddinge, Sweden.

Abbreviations: IATS, International Antigenic Typing Scheme; IROMP, iron-regulated outer membrane protein; LPS, lipopolysaccharide; mAbs, monoclonal antibodies; OM, outer membrane; PBS, phosphate buffered saline; TBS, Tris-buffered saline. system are high molecular mass, iron-regulated outer membrane proteins (IROMPs), produced under conditions of iron deprivation, which act as receptors to facilitate the uptake of iron-siderophore complexes (Neilands, 1982). Pseudomonas aeruginosa expresses several high molecular mass IROMPs in vivo, in both chronic (Brown et al., 1984; Cochrane et al., 1988) and acute infections (Ward et al., 1988). A $14 \mathrm{kDa}$ outer membrane protein has been reported as the receptor for the $P$. aeruginosa siderophore ferripyochelin (Sokol \& Woods, 1983). Antibodies directed against proteins associated with iron uptake may exert a bacteriostatic effect by blocking ferric siderophore-mediated uptake and therefore have considerable potential as immunotherapeutic agents. When considering outer membrane (OM) components as vaccine candidates, proteins are generally less serotype-specific than other components such as lipopolysaccharide (LPS) and should therefore be more appropriate for immunoprotective and immunodiagnostic studies. Antibodies directed against such proteins should be cross-reactive with strains of different serotypes. OM porin protein $\mathrm{F}$, lipoprotein I and protein $\mathrm{H}_{2}$ have been shown to cross-react immunologically between the different serotypes of $P$. aeruginosa (Mutharia et al., 1982) and have been the subject of 
investigations as to the protective potential of antibodies directed against them. Gilleland et al. (1984) reported that a purified protein $F$ preparation successfully protected mice, after either passive or active immunization, from a subsequent challenge with a heterologous LPS immunotype of $\boldsymbol{P}$. aeruginosa. Using a burned mouse model these workers demonstrated greater protection after immunization with a porin protein $F$ preparation than with LPS immunization (Matthews-Greer \& Gilleland, 1987). Hancock et al. (1985) have also demonstrated the immunotherapeutic potential of monoclonal antibodies (mAbs) to $P$. aeruginosa porin protein F. Reports of the use of IROMPs as vaccine components are scant. Bolin \& Jensen (1987) have demonstrated passive protection against Escherichia coli septicaemia in turkeys using polyclonal antisera reactive against IROMPs. Sokol \& Woods (1986a) demonstrated straindependent passive protection with polyclonal antisera raised against the $14 \mathrm{kDa}$ ferripyochelin binding protein and showed that mAbs directed against this protein reduced ferripyochelin binding and promoted phagocytosis of $P$. aeruginosa by human polymorphonuclear neutrophils (Sokol \& Woods, 1986b). Purified polyclonal antisera raised against an $80 \mathrm{kDa}$ IROMP inhibited the uptake of ferri-pyoverdine by $P$. aeruginosa PAO (Cornelis et al., 1989). Interestingly, in this study, pyoverdine-type specificity was noted (Cornelis et al., 1989), wherein polyclonal antisera were directed only against IROMPs from strains producing structurally similar pyoverdine molecules. Three pyoverdine-specific groups were identified. To explore the immunotherapeutic potential of $P$. aeruginosa IROMPs, we have partially purified these proteins to circumvent the immunodominant response to LPS and used this preparation to raise mAbs. We have used immunogold electron microscopy to investigate the interaction between these antibodies and intact cells of $P$. aeruginosa.

\section{Methods}

Bacterial strains and culture conditions. P. aeruginosa PAO1 (ATCC 15692) and AK 1282, an LPS defective mutant of PAO obtained from Dr A. M. Kropinski (Jarrell \& Kropinski, 1981), were used. Representative strains of the 17 International Antigenic Typing Scheme (IATS) serotypes of $P$. aeruginosa were clinical isolates in the University of Aston culture collection. Strains were routinely maintained on nutrient agar (Oxoid) slopes at $4{ }^{\circ} \mathrm{C}$ and cultured in an irondepleted chemically defined simple salts medium ( $\mathrm{CDM}-\mathrm{Fe}$ ) comprising $5 \mathrm{~mm}-\mathrm{NaCl}, 0.062 \mathrm{mM}-\mathrm{KCl}, 0.4 \mathrm{mM}-\mathrm{MgSO}_{4}, 3 \cdot 2 \mathrm{mM}-\mathrm{K}_{2} \mathrm{HPO}_{4}$, $40 \mathrm{~mm}-\left(\mathrm{NH}_{4}\right)_{2} \mathrm{SO}_{4}, 50 \mathrm{~mm}-\mathrm{MOPS}, \mathrm{pH} 7 \cdot 4$, and $40 \mathrm{~mm}$-glucose (Brown et al., 1984). Iron-replete cells were grown in the chemically defined medium with $0.062 \mathrm{~mm}-\mathrm{FeSO}_{4} \cdot 7 \mathrm{H}_{2} \mathrm{O}(\mathrm{CDM}+\mathrm{Fe})$. Bacteria were grown in $\mathrm{CDM}-\mathrm{Fe}$ or $\mathrm{CDM}+\mathrm{Fe}$ to early stationary phase $\left(\mathrm{OD}_{470} 1 \cdot 0\right)$ in an orbital shaking incubator at $37^{\circ} \mathrm{C}$, harvested by centrifugation at $10000 \mathrm{~g}$ for $10 \mathrm{~min}$ and washed once with saline.
Preparation of the antigen. OMs were prepared by the method of Filip et al. (1973). The washed bacterial pellet, containing approximately $2 \times 10^{11}$ cells, was suspended in $20 \mathrm{ml}$ distilled water and broken by $10 \times 60 \mathrm{~s}$ pulses of sonication in an ice bath, with $60 \mathrm{~s}$ intervals for cooling. Unbroken cells were removed by centrifugation at $10000 \mathrm{~g}$ for 10 min. Sarkosyl ( $N$-lauryl sarcosinate, sodium salt; Sigma) and EDTA were added to the supernate to final concentrations of $2 \%(w / v)$ and $10 \mathrm{mM}$, respectively. The mixture was incubated at room temperature for $1 \mathrm{~h}$ and then centrifuged at $100000 \mathrm{~g}$ for $1 \mathrm{~h}$. The OM pellets were washed twice by suspending in distilled water and centrifuging at $100000 \mathrm{~g}$ for $1 \mathrm{~h}$. The washed OM pellet was extracted with $5 \mathrm{ml}$ solubilization buffer comprising 0.3\% (v/v) Empigen BB (Albright \& Wilson), $10 \mathrm{~mm}$-EDTA, $1 \mathrm{~mm}$-phenylmethylsulphonyl fluoride, $0.02 \%$ (w/v) sodium azide and $20 \mathrm{~mm}$-triethanolamine, $\mathrm{pH} 7 \cdot 5$, for $1 \mathrm{~h}$ at room temperature. The supernatant was recovered after centrifugation at $100000 \mathrm{~g}$ for $1 \mathrm{~h}$ and stored at $-20^{\circ} \mathrm{C}$.

Gel-filtration chromatography. A Superose 12 gel filtration column (Pharmacia) was used with a modified deoxycholate running buffer (Heckels, 1977) comprising 1\%(w/v) sodium deoxycholate (Sigma), $10 \mathrm{~mm}$-EDTA, $1 \mathrm{~mm}$ PMSF, $20 \mathrm{~mm}$-triethanolamine, pH 9.5. A $500 \mu \mathrm{l}$ sample of Empigen BB solubilized OM preparation $\left(1 \mathrm{mg}\right.$ protein $\left.\mathrm{ml}^{-1}\right)$ was injected onto the column. A flow rate of $0.5 \mathrm{ml} \mathrm{min}^{-1}$ was used and $1 \mathrm{ml}$ fractions were collected. Protein elution was monitored in-line by measuring $A_{280}$. The fractions were dialysed against $20 \mathrm{~mm}$-triethanolamine, pH 9.5, for $24 \mathrm{~h}$ prior to concentration by freeze-drying. Aliquots of each fraction were analysed by sodium dodecyl sulphatepolyacrylamide gel electrophoresis (SDS-PAGE) and immunoblotting. Fractions containing IROMPs were pooled and the protein content determined by a modified Lowry method.

Preparation of flagella. The method of Montie et al. (1982) was used. $P$. aeruginosa AK 1282 was grown in 8 litres CDM - Fe and shaken at 50 r.p.m. for $48 \mathrm{~h}$ at $37^{\circ} \mathrm{C}$. The cells were harvested by centrifugation at $10000 \mathrm{~g}$ for $10 \mathrm{~min}$ and suspended in $20 \mathrm{ml}$ saline. The flagella were sheared by treatment in a commercial blender for $10 \mathrm{~s}$ and isolated by differential centrifugation. The suspension was centrifuged at $10000 \mathrm{~g}$ for $10 \mathrm{~min}$ to remove whole cells and the supernatant centrifuged at $100000 \mathrm{~g}$ for $4 \mathrm{~h}$ to precipitate the flagella. This procedure was repeated until a clear pellet was obtained. The pellet was resuspended in $1 \mathrm{ml}$ distilled water and stored at $-20^{\circ} \mathrm{C}$.

Immunization schedule. An aliquot of pooled antigen equivalent to $50 \mu \mathrm{g}$ protein was emulsified with an equal volume of Freund's complete adjuvant (Sigma) and injected subcutaneously into $F_{1}$ $(\mathrm{CBA} \times \mathrm{Balb} / \mathrm{c})$ mice. Four weeks later, $50 \mu \mathrm{g}$ antigen emulsified in Freund's incomplete adjuvant (Sigma) was injected intraperitoneally. After a further 4 weeks a final boost of $10 \mu \mathrm{g}$ antigen was given intravenously. Blood samples were taken during the immunization schedule and immediately prior to fusion. Immunoblotting and ELISA assays were performed to determine the level and specificity of circulating antibody. Three days after the last injection the spleen cells of mice giving a strong antibody response by immunoblotting were fused with the NS1 myeloma cell line (Kohler \& Milstein, 1976).

Selection and cloning of hybridomas. The hybridomas were screened for specific antibody production using an ELISA technique. Nunc microELISA plates (Gibco, UK) were coated overnight with $100 \mu \mathrm{l}$ of iron-depleted $P$. aeruginosa AK $1282 \mathrm{OMs} 2 \mu \mathrm{g} \mathrm{ml}^{-1}$ in $50 \mathrm{mM}$ carbonate/bicarbonate buffer, $\mathrm{pH}$ 9.6. Plates were washed in isotonic phosphate-buffered saline (PBS) containing 0.05\% (v/v) Tween 20 (PBS/Tween) and blocked with $200 \mu 10.05 \%$ (w/v) fish gelatin (Sigma) in PBS for $1 \mathrm{~h}$ at $37^{\circ} \mathrm{C}$. After washing thoroughly, the plates were incubated at $37^{\circ} \mathrm{C}$ for $1 \mathrm{~h}$ with $50 \mu \mathrm{l}$ volumes of hybridoma supernatants, diluted $1: 2$ in PBS/Tween. Plates were washed three times in PBS/Tween and $100 \mu 11: 1000$ anti-mouse $F\left(a b^{\prime}\right)_{2}$ fragments conjugated to horseradish peroxidase (Amersham) in PBS/Tween and 
$1 \%(\mathrm{v} / \mathrm{v})$ sheep serum was added to each well and incubated at $37{ }^{\circ} \mathrm{C}$ for $1 \mathrm{~h}$. Plates were washed and developed with $100 \mu \mathrm{l} 0.0058 \%$ (w/v) 3,3',5,5'-tetramethylbenzidine in $0 \cdot 1 \mathrm{M}$-acetate buffer, $\mathrm{pH} 5 \cdot 2$ for $10 \mathrm{~min}$; the reaction was stopped with $50 \mu \mathrm{l} 2 \mathrm{M}$-sulphuric acid. $A_{450}$ was measured using a Multiscan microplate reader (Flow Laboratories). For the second screen the ELISA was repeated as above, but LPS from AK $1282\left(2 \mu \mathrm{g} \mathrm{ml}^{-1}, 100 \mu \mathrm{l}\right.$ per well), purified by the hot-phenol method (Westphal \& Jann, 1965) was used as the antigen coat.

Determination of antibody isotype. Various specific murine Ig isotype antibodies were used in an ELISA isotyping assay. ELISA plates coated with AK $1282 \mathrm{OMs}$ as described above were incubated with hybridoma supernatants for $1 \mathrm{~h}$ at $37^{\circ} \mathrm{C}$. After washing, $100 \mu \mathrm{l} 1: 1000$ biotinylated sheep anti-murine IgM, IgG1, IgG2a, IgG2b and IgG3 isotype conjugates (Amersham) in PBS/T ween were incubated at $37^{\circ} \mathrm{C}$ for $1 \mathrm{~h}$. The plates were washed and incubated with $100 \mu \mathrm{l}$ streptavidinhorse radish peroxidase (Amersham) for $20 \mathrm{~min}$ at $37^{\circ} \mathrm{C}$. The colour reaction was developed as described above.

$S D S-P A G E$. This was performed on $12 \%(\mathrm{w} / \mathrm{v})$ acrylamide gels (Laemmli, 1970) in a Mini-Protean apparatus (Bio-Rad). Gels were stained with $0.1 \%(\mathrm{w} / \mathrm{v})$ Coomassie Brilliant blue R-250 in methanol/ water/acetic acid ( $50: 40: 10$, by vol.) and destained in water/methanol/ acetic acid $(83: 10: 7$, by vol.). If LPS antigenic sites were to be investigated, OM preparations were incubated with $2.5 \mathrm{mg}$ proteinase $\mathrm{K}$ (Sigma) $\mathrm{ml}^{-1}$ in sample buffer comprising $50 \mathrm{mM}$-Tris $/ \mathrm{HCl}(\mathrm{pH} 6.8)$, $2 \%(\mathrm{w} / \mathrm{v})$ SDS, $10 \%(\mathrm{v} / \mathrm{v})$ glycerol, $1 \%(\mathrm{v} / \mathrm{v}) 2$-mercaptoethanol for $1 \mathrm{~h}$ at $60{ }^{\circ} \mathrm{C}$ prior to electrophoresis. Silver staining was done by the method of Tsai \& Frasch (1982).

Immunoblotting procedure. Proteins and LPS separated by SDSPAGE were electroblotted to nitrocellulose by the method of Towbin $e t$ al. (1979) using a Transblot apparatus (Bio-Rad). Transfer of proteins was confirmed by staining with $1 \%(\mathrm{w} / \mathrm{v})$ amido black in water/methanol/acetic acid (83:10:7, by vol.). The nitrocellulose was cut into strips and incubated at $37^{\circ} \mathrm{C}$ for $1 \mathrm{~h}$ in $5 \%(\mathrm{w} / \mathrm{v})$ skimmed milk in $10 \mathrm{~mm}$-Tris-buffered saline (TBS), pH 7.4, to block non-specific antibody binding. The nitrocellulose strips were incubated for $4 \mathrm{~h}$ at $37^{\circ} \mathrm{C}$ with hybridoma supernatant $1: 50$ in TBS/milk. The blots were washed three times in TBS and incubated with $1: 1000$ protein A (from Staphylococcus aureus) conjugated to horseradish peroxidase (Sigma) in TBS/milk for $2 \mathrm{~h}$ at $37^{\circ} \mathrm{C}$. The antigenic components were visualized with $0.0025 \%(\mathrm{w} / \mathrm{v}) 4$-chloro-1-naphthol (Sigma) in $0.01 \%(\mathrm{v} / \mathrm{v}) \mathrm{H}_{2} \mathrm{O}_{2}$ with $10 \mathrm{~mm}-\mathrm{Tris} / \mathrm{HCl}$, at $\mathrm{pH} 7 \cdot 4$.

Immunogold electron microscopy. P. aeruginosa strains PAO1 and AK 1282 were grown in CDM-Fe to the late exponential phase, harvested by centrifugation at $10000 \mathrm{~g}$ for $10 \mathrm{~min}$ and fixed in $0.1 \%$ $(\mathrm{v} / \mathrm{v})$ glutaraldehyde in saline. Aliquots $(1 \mathrm{ml})$ of fixed cells $\left(10^{8} \mathrm{ml}^{-1}\right)$ were washed in PBS and suspended in $200 \mu \mathrm{l}$ PBS. Aliquots $(10 \mu \mathrm{l})$ were incubated with $90 \mu \mathrm{l}$ hybridoma supernatant (diluted $1: 2$ in PBS) or $90 \mu$ polyclonal serum (diluted $1: 100$ in PBS) for $1 \mathrm{~h}$ at $37^{\circ} \mathrm{C}$. The cells were then washed and suspended in $40 \mu \mathrm{l} \mathrm{PBS}$. Aliquots $(20 \mu \mathrm{l})$ were pipetted onto Parafilm (American Can Co.). Inverted electron microscope grids (Agar Aids, UK) were placed onto the samples. After 10 min the grids were blotted, washed and incubated with 1:10 goat anti-mouse IgG immunogold conjugate $(15 \mathrm{~nm}$ particle size, BioCell Ltd) in a humidified box overnight at $4{ }^{\circ} \mathrm{C}$. The grids were washed, counterstained in $0.5 \%(\mathrm{w} / \mathrm{v})$ phosphotungstic acid for $1 \mathrm{~min}$, washed again and examined under a Philips EM 300 electron microscope.

Cell surface iodination. Iodination was performed using Iodo-Beads (Pierce Chemical Co.) in accordance with the manufacturer's instructions. A $1 \mathrm{ml}$ aliquot of bacterial cells $\left(10^{8} \mathrm{ml}^{-1}\right.$ in PBS) was added to a reaction vial containing two lodo-beads. A $20 \mu \mathrm{l}$ volume of ${ }^{125} \mathrm{I}$ (Amersham) diluted into PBS $\left(10 \mathrm{mCi} \mathrm{ml}^{-1} ; 370 \mathrm{MBq} \mathrm{ml}^{-1}\right)$ was added to the reaction vial to give $0.2 \mathrm{mCi}{ }^{125} \mathrm{I}$ per reaction vial. The samples were swirled gently at room temperature for $5 \mathrm{~min}$. The reaction was terminated by removal of the Iodo-Beads and addition of $1 \mathrm{ml} 10 \mathrm{~mm}$-sodium iodide/PBS (NaI/PBS). The radiolabelled cells were washed six times by centrifugation $(10000 \mathrm{~g}$ for $5 \mathrm{~min})$ and suspension in $1 \mathrm{ml} \mathrm{NaI/PBS}$. After the last wash the cell pellets were suspended in $100 \mu \mathrm{l}$ SDS-PAGE sample buffer, boiled for $10 \mathrm{~min}$ and then $20 \mu \mathrm{l}$ aliquots were electrophoresed on $12 \%(\mathrm{w} / \mathrm{v})$ SDS-polyacrylamide gels. After SDS-PAGE, the gels were dried onto filter paper by heating under reduced pressure. Dried gels were exposed to Kodak XAR film (Eastman Kodak Co.) for 4 days at $-70{ }^{\circ} \mathrm{C}$ to obtain an autoradiogram of the labelled proteins.

\section{Results}

\section{Purification of IROMPS}

In order to produce anti-OM protein $\mathrm{mAbs,}$ it was necessary to purify the antigen preparation from LPS and so circumvent the immunodominant response to this antigen. The LPS-defective mutant, $P$. aeruginosa AK 1282, reported to have LPS comprising only lipid A and core components (Jarrell \& Kropinski, 1981), was grown in an iron-limited chemically-defined medium which has been shown previously to induce OM protein profiles with similar characteristics to those isolated from cells in vivo (Brown et al., 1984; Anwar et al., 1984). An IROMP-enriched preparation was obtained by selective solubilization of OMs from the LPS-defective mutant $P$. aeruginosa AK 1282 in $0.3 \%(\mathrm{v} / \mathrm{v})$ Empigen BB. With selective solubilization, the IROMPs represented $52 \%$ of total protein compared with $22.5 \%$ for OM preparations as judged by densitometric scanning of Coomassie blue-stained SDS-polyacrylamide gels (results not shown). Preliminary studies raising polyclonal antisera to IROMPs prepared by excision and elution from SDS-polyacrylamide gels indicated that this method of purification yielded an antigen preparation with a high LPS content (results not shown). The IROMPs were purified further by gel-filtration chromatography with a deoxycholate separation buffer. Analysis of column fractions by SDS-PAGE and silver staining after treatment with proteinase $K$ revealed the presence of LPS contamination in the protein fractions (results not shown). Immunoblotting using polyclonal rabbit antisera specific for $P$. aeruginosa AK $1282 \mathrm{OMs}$ was employed to study the protein profile of the column fractions (Fig. $1 a$ ), and, after proteinase $\mathrm{K}$ digestion, to reveal LPS antigenic sites (Fig. $1 b$ ). Whilst the IROMPs present in fractions 6 to 15 were separated from lipid A, they were contaminated with low amounts of the Oantigenic moiety of LPS, indicating that AK1282 is not completely O-antigen deficient. 
(a)

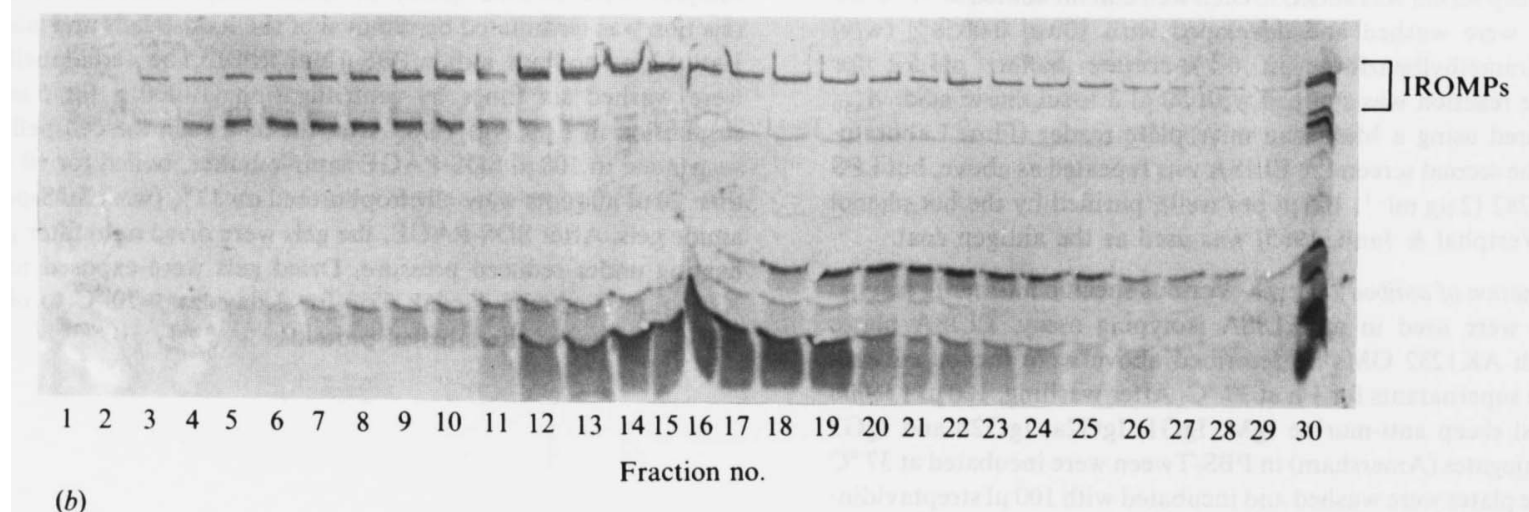

(b)

\begin{abstract}
Fraction no.
\end{abstract}

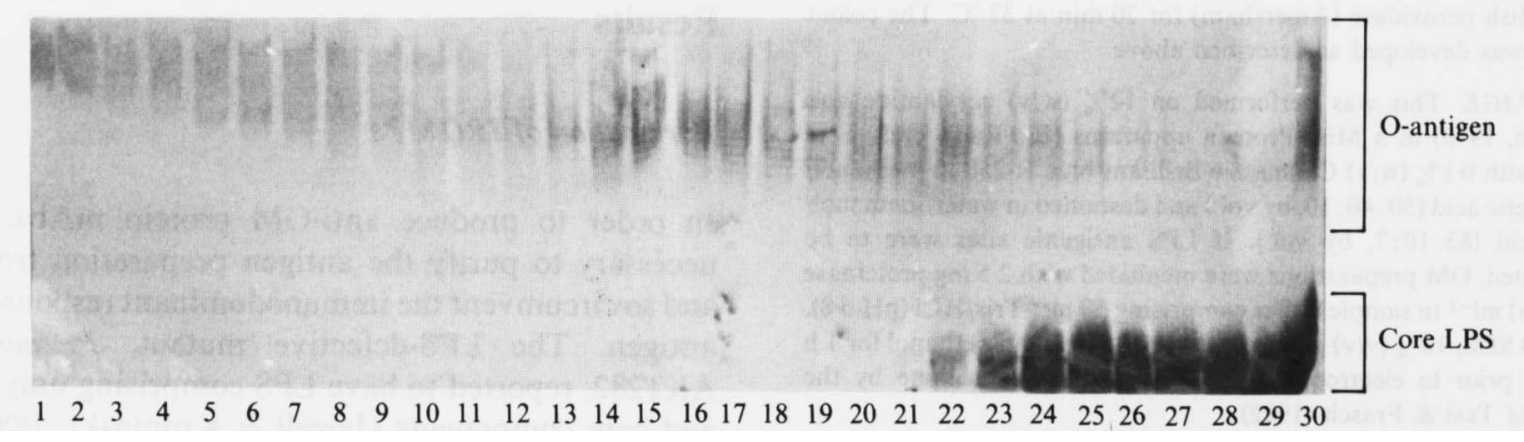

Fraction no.

Fig. 1. Immunoblot analysis of fractions from gel-filtration chromatography of Empigen BB-solubilized OMs of P. aeruginosa AK 1282 . Fractions 1 to 29 (lanes 1 to 29) and extract (lane 30) for protein $(a)$ and LPS $(b)$ were probed with serum raised to OMs of $P$. aeruginosa grown in $\mathrm{CDM}-\mathrm{Fe}$ and developed with protein A-peroxidase. Fraction 30 shows the profile of the extract prior to gel filtration.

\section{Isolation of $m A b s$}

After fusion of NS1 myeloma cells with spleen cells of mice immunized with the partially purified IROMP preparation, hybridomas producing antibodies specific for $P$. aeruginosa AK1282 OMs were cloned by limiting dilution until a single clone in each well was obtained. To eliminate hybridomas secreting anti-LPS antibodies, a second ELISA screen was used employing purified AK 1282 LPS as the antigen coat. Only three out of 46 hybridomas reacted with LPS. Fourteen of the selected hybridomas were stable in culture. These were classified in terms of immunoglobulin isotype and ELISA titre against AK 1282 OMs (Table 1). Nine of the mAbs were of the IgG2a subclass, four were IgG2b and one was $\mathrm{IgG} 1$. There was no correlation between ELISA titre and antibody isotype.

\section{Interaction of $m A$ Abs with P. aeruginosa AK1282 OMs}

Immunoblotting was performed to determine the antigen specificity of the mAbs listed in Table 1. mAbs C14, C16, $\mathrm{C} 19, \mathrm{C} 103$ and $\mathrm{C} 108$ reacted strongly with the $85 \mathrm{kDa}$ IROMP; however, the reactions were not completely
Table 1. Classification of $m A$ bs

\begin{tabular}{lcr}
\hline \hline mAb & $\begin{array}{c}\text { Immunoglobulin } \\
\text { isotype }\end{array}$ & $\begin{array}{r}\text { Titre in } \\
\text { ELISA }^{*}\end{array}$ \\
\hline $\mathrm{C} 9$ & IgG1 & 12000 \\
$\mathrm{C} 12$ & IgG2a & 7000 \\
$\mathrm{C} 13$ & IgG2b & 10000 \\
$\mathrm{C} 14$ & IgG2a & 9500 \\
$\mathrm{C} 15$ & IgG2a & 8500 \\
$\mathrm{C} 16$ & IgG2b & 6500 \\
$\mathrm{C} 19$ & IgG2a & 8000 \\
$\mathrm{C} 23$ & IgG2a & 12500 \\
$\mathrm{C} 24$ & IgG2a & 10500 \\
$\mathrm{C} 28$ & IgG2a & 13000 \\
$\mathrm{C} 31$ & IgG2b & 10000 \\
$\mathrm{C} 32$ & IgG2a & 12500 \\
$\mathrm{C} 103$ & IgG2a & 9000 \\
C108 & IgG2b & 8000 \\
\hline \hline
\end{tabular}

* Purified AK 1282 OMs were used at a concentration of $2 \mu \mathrm{g}$ per well in the ELISA.

specific since cross-reactivity with OM components of lower molecular mass was noted (Fig. $2 a$ ). mAbs 9, 12, $13,15,23,24,28,31$ and 32 reacted against a $54 \mathrm{kDa}$ antigen which was barely detectable on an amido-black- 

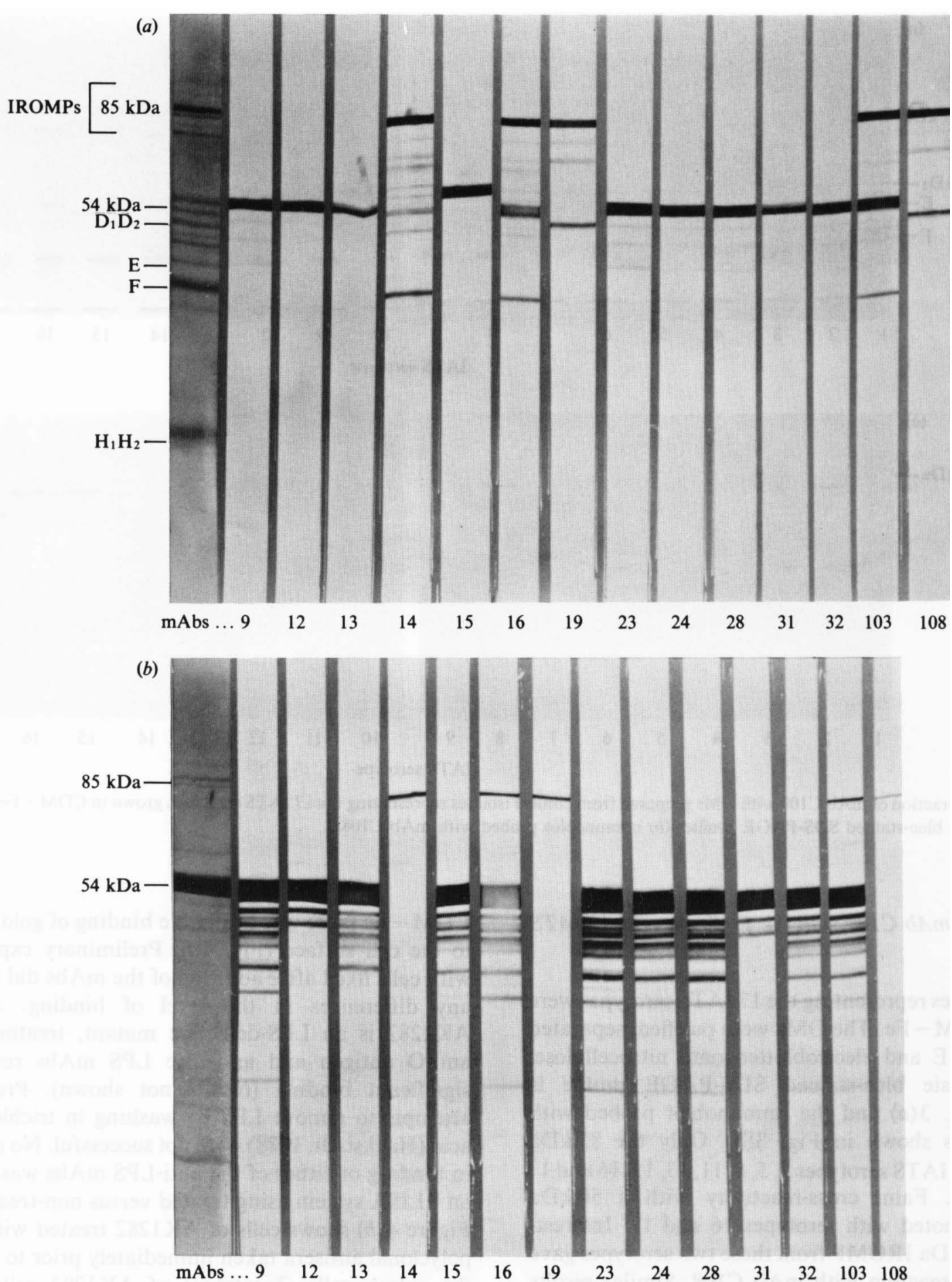

Fig. 2. Strip immunoblots of OM proteins $(a)$ and flagella $(b)$ prepared from $P$. aeruginosa AK1282. The strips were probed with hybridoma end supernatants ( $\mathrm{C} 9$ to $\mathrm{C} 108)$ and developed with protein $\mathrm{A}$-peroxidase. The leftmost lane $(a$ and $b)$ shows a nitrocellulose strip stained with amido black.

stained nitrocellulose strip. Similar strong reactions were noted against a purified preparation of flagella which migrated with the same apparent molecular mass (Fig. $2 b$ ), suggesting that these mAbs were directed against flagellar proteins. LPS immunoblots were performed to determine if the observed cross-reactivity was attributable to anti-LPS activity against co-migrating LPS. None of the mAbs reacted against LPS (results not shown), indicating that the screening strategy had resulted in a panel of anti-OM protein mAbs. 

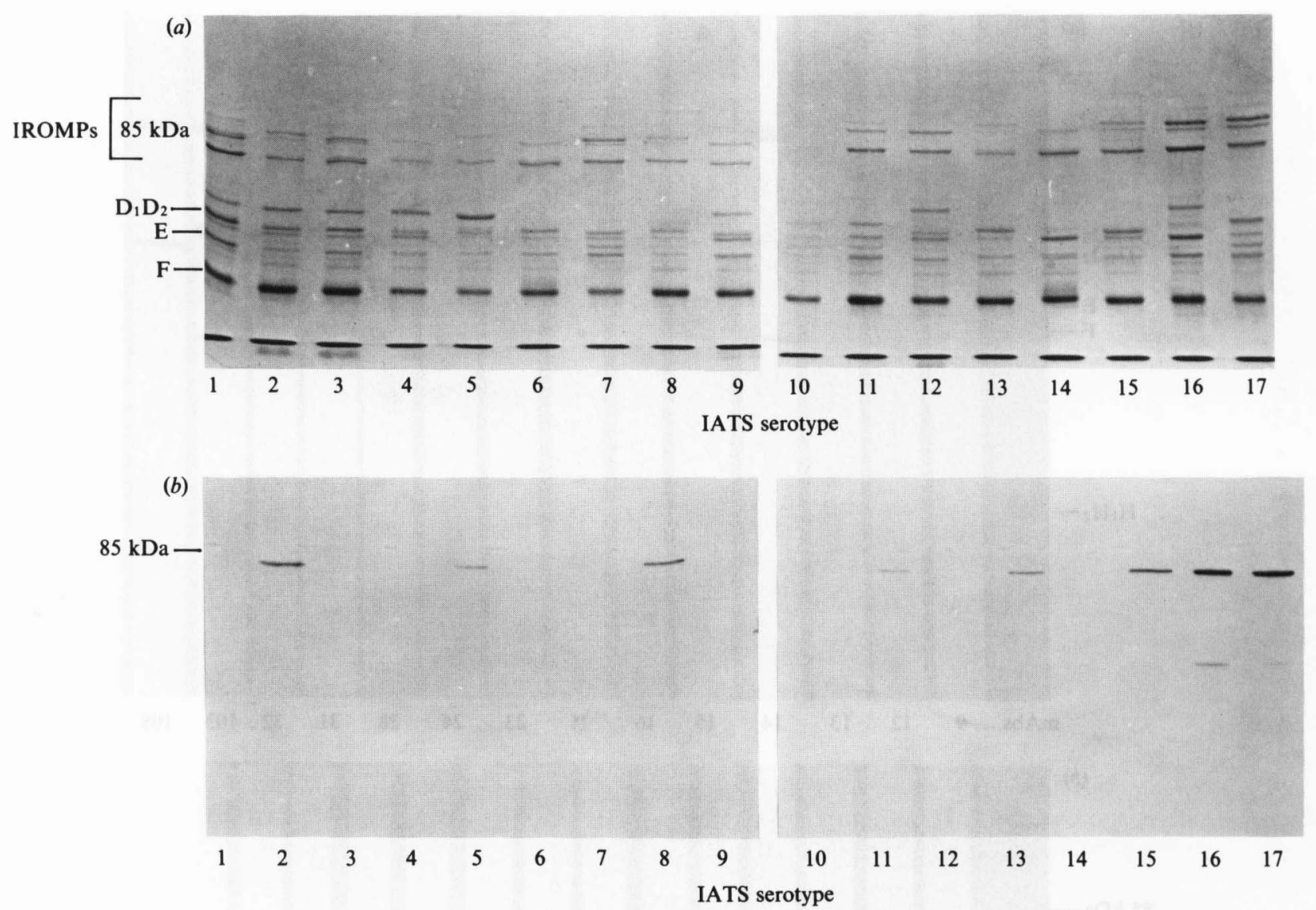

Fig. 3. Interaction of $\mathrm{mAb} \mathrm{C108}$ with $\mathrm{OMs}$ prepared from clinical isolates representing the 17 IATS serotypes grown in $\mathrm{CDM}-\mathrm{Fe}$. (a) Coomassie blue-stained SDS-PAGE profile; $(b)$ immunoblot probed with mAb C108.

Interaction of $m A b C 108$ with the 17 P. aeruginosa IATS serotypes

Clinical isolates representing the 17 IATS serotypes were grown in CDM - Fe. The OMs were purified, separated by SDS-PAGE and electroblotted onto nitrocellulose. The Coomassie blue-stained SDS-PAGE profile is shown in Fig. 3(a) and the immunoblot probed with $\mathrm{mAb} \mathrm{C108}$ is shown in Fig. $3(b)$. Only the $85 \mathrm{kDa}$ IROMP from IATS serotypes 2, 5, 8, 11, 13, 15, 16 and 17 was detected. Faint cross-reactivity with a $50 \mathrm{kDa}$ antigen was noted with serotypes 16 and 17 . Interestingly, the $85 \mathrm{kDa}$ IROMP from these two serotypes gave the strongest reaction with $\mathrm{mAb} \mathrm{C108}$. Similar results were noted with the other anti-85 kDa mAbs (results not shown).

\section{Interaction of $m A b s$ with intact cells}

Immunogold electron microscopy was used to assess the surface exposure of the $85 \mathrm{kDa}$ IROMP. When $\mathrm{mAb}$ C108 was reacted with cells of strain AK 1282 grown in
CDM - Fe there was negligible binding of gold particles to the cell surface (Fig. 4a). Preliminary experiments with cells fixed after addition of the mAbs did not show any differences in the level of binding. Although AK 1282 is an LPS-defective mutant, treatment with anti-O antigen and anti-core LPS mAbs resulted in significant binding (results not shown). Preliminary attempts to remove LPS by washing in trichloroacetic acid (Hackstadt, 1988) were not successful. No reduction in binding of either of the anti-LPS mAbs was noted in an ELISA system using treated versus non-treated cells. Figure 4(b) shows cells of AK1282 treated with mouse polyclonal antisera taken immediately prior to fusion of the spleen cells. Treatment of AK1282 cells with a control antibody, mouse anti-human luteinizing hormone, did not result in any binding (results not shown). Two of the anti-85 kDa IROMP mAbs, C19 and C103, agglutinated cells of AK1282 grown in low-iron medium, but not in high-iron medium. Figure $5(a)$ shows the reaction of low-iron-grown AK1282 cells with mouse polyclonal antiserum taken prior to fusion and the agglutination with mAb C19 is shown in Fig. 5(b). 

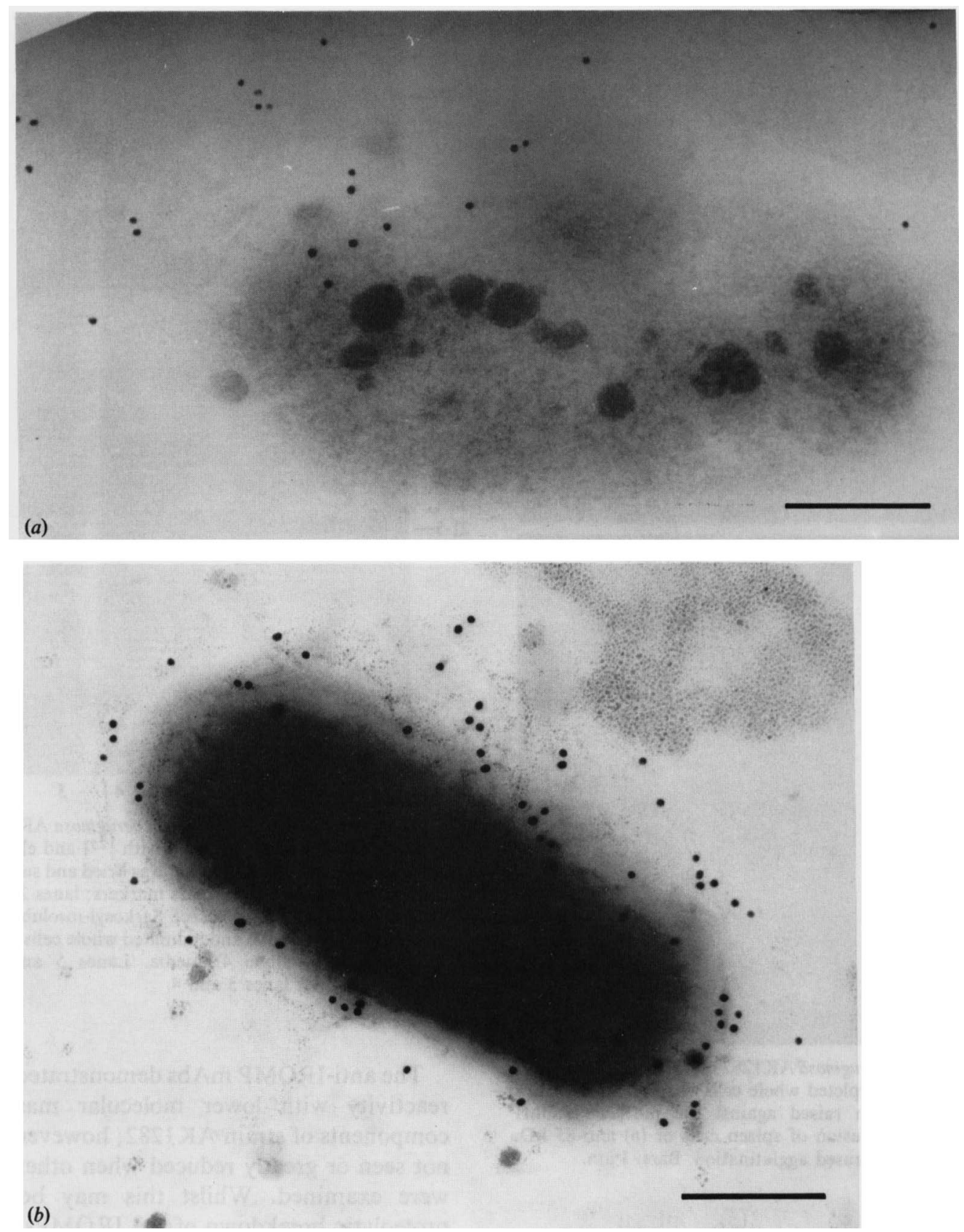

Fig. 4. Immunogold detection of surface antigenic sites of $P$. aeruginosa AK 1282. Iron-depleted whole cells of AK 1282 were reacted with anti-85 kDa IROMP mAb C108 (a) and mouse polyclonal antiserum raised to purified IROMPs $(b)$. Bars, $0.5 \mu \mathrm{m}$.

\section{Cell surface iodination}

Since the reaction of anti-85 kDa IROMP mAb 108 with whole cells of low-iron-grown AK1282 was not conclusive, cell surface iodination was attempted to determine if the $85 \mathrm{kDa}$ IROMP was surface exposed. The autoradiograph of AK1282 cells grown in both $\mathrm{CDM}+\mathrm{Fe}$ and $\mathrm{CDM}-\mathrm{Fe}$ is shown in Fig. 6, together with the corresponding Coomassie blue-stained SDS-
PAGE profiles. A strongly-labelled band corresponding to the $85 \mathrm{kDa}$ IROMP was present in CDM-Fe cells but absent in those grown in $\mathrm{CDM}+\mathrm{Fe}$.

\section{Discussion}

The major obstacle in the purification of Gram-negative OM proteins for immunological studies is the difficulty 

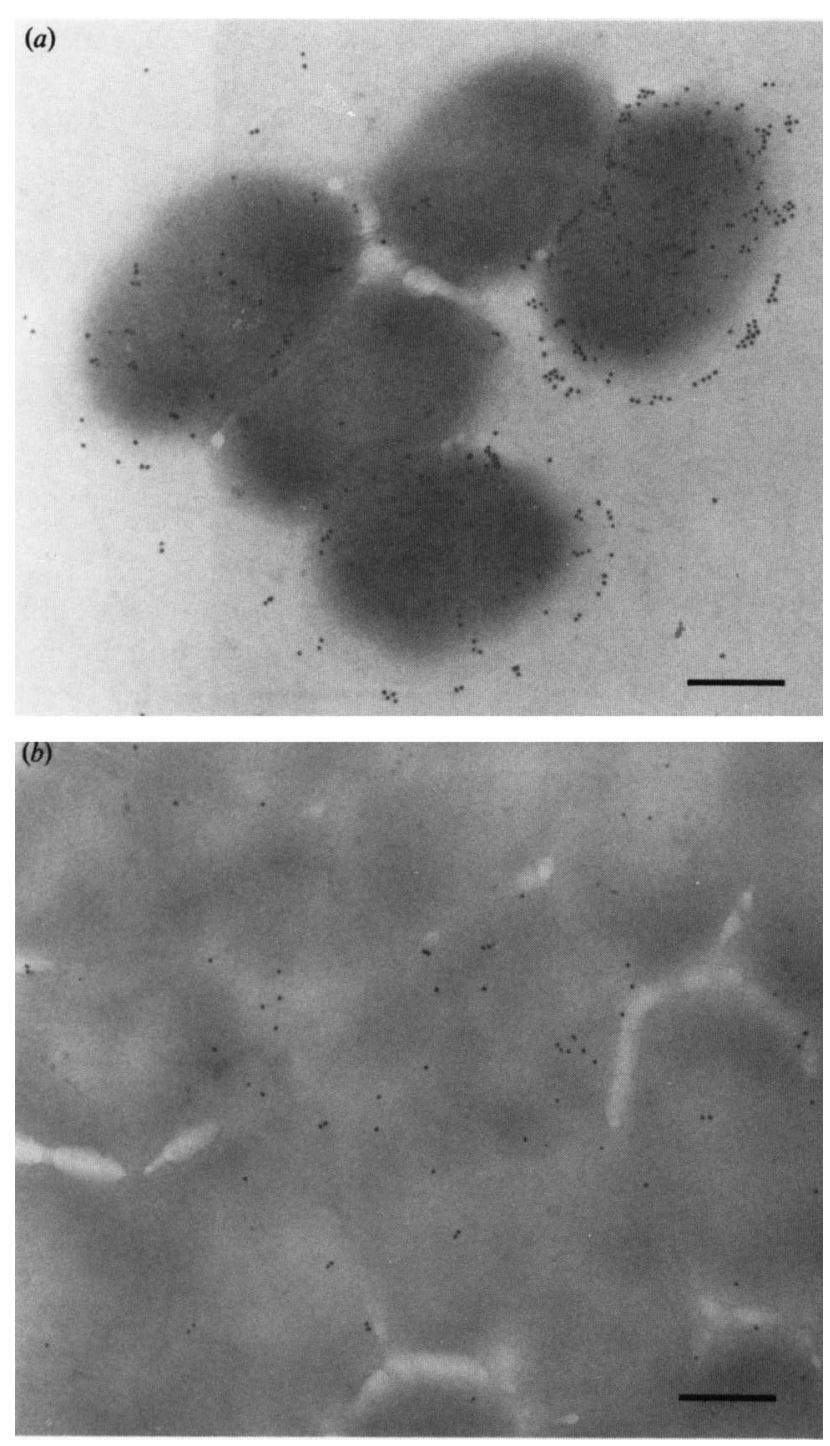

Fig. 5. Agglutination of $P$. aeruginosa AK 1282 revealed by immunogold electron microscopy. Iron-depleted whole cells were reacted with $(a)$ mouse polyclonal antiserum raised against the purified IROMP preparation taken prior to fusion of spleen cells or $(b)$ anti-85 kDa IROMP mAb C19, which caused agglutination. Bars, $1 \mu \mathrm{m}$.

of separating them from the LPS with which they are intrinsically associated. Deoxycholate gel-filtration chromatography, noted for breakdown of LPS into monomeric subunits (Heckels, 1977), effected separation of the IROMPs from the lipid A component of LPS and enabled us to produce a panel of anti-OM protein mAbs. In this work we have characterized a panel of nine antiflagella $\mathrm{mAbs}$ and five $\mathrm{mAbs}$ which react against the $85 \mathrm{kDa}$ IROMP of $P$. aeruginosa AK 1282. The isolation of anti-flagella $\mathrm{mAbs}$ is not surprising since flagella are recognized as dominant $P$. aeruginosa antigens (Ward $e t$ al., 1988) with protective capability (Holder $\&$ Naglich, 1986).

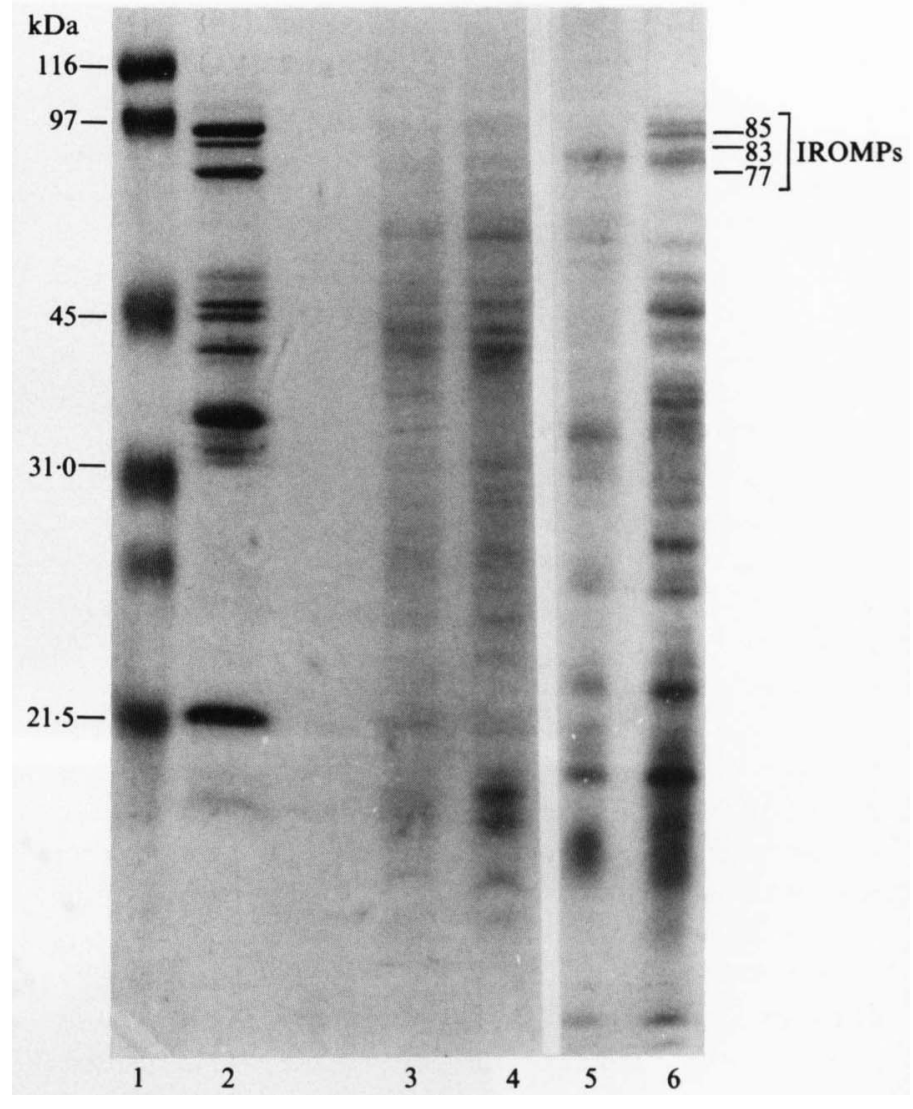

Fig. 6. Cell surface iodination of $P$. aeruginosa AK1282. Whole cells of $P$. aeruginosa were radiolabelled with ${ }^{125} I$ and electrophoresed on an SDS-polyacrylamide gel. The gel was dried and subjected to autoradiography. Lane 1, molecular mass markers; lanes 2-4, Coomassie bluestained SDS-PAGE profiles of Sarkosyl-insoluble OMs of low-iron grown AK1282 (lane 2) and iodinated whole cells grown in high- (lane 3) and low-iron (lane 4) media. Lanes 5 and 6, corresponding autoradiogram of lanes 3 and 4 .

The anti-IROMP mAbs demonstrated low-level crossreactivity with lower molecular mass $\mathrm{OM}$ protein components of strain AK1282; however, this was either not seen or greatly reduced when other clinical strains were examined. Whilst this may be due either to proteolytic breakdown of the IROMPs or to conserved epitopes, it is not clear why $\mathrm{mAb} \mathrm{C108}$ should be specific for the $85 \mathrm{kDa}$ IROMP in one strain but not in another. The pattern of cross-reactivity amongst the five mAbs against OMs prepared from AK1282 grown in $\mathrm{CDM}-\mathrm{Fe}$ is different, suggesting that different epitopes are being recognized. Cross-reactivity among the IROMPs $(72-115 \mathrm{kDa})$ was noted by Cornelis et al. (1987), but not with other OM protein components. The pattern of cross-reactivity amongst the 17 IATS serotypes was surprising; the IROMPs have been postulated to be involved in uptake of iron-siderophore complexes and so it would be expected that such a system would be common to $P$. aeruginosa strains. Our immunoblotting 
data support the findings of Cornelis et al. (1989) that $P$. aeruginosa has immunologically distinct IROMPs of a similar molecular mass. It is not clear whether the approximately $85 \mathrm{kDa}$ IROMP in this study is the same as the $80 \mathrm{kDa}$ pyoverdine receptor reported by Cornelis et al. (1989), nor, as is suggested by these authors, is it clear why proteins having the same molecular mass and apparent biochemical function should exhibit antigenic variation and be immunologically distinct. It is noteworthy that Christoffersen \& Cox (1989) have described heterogeneous forms of pyoverdine, varying in the composition of the amino acid side-chain, both within the same strain and from different strains of $P$. aeruginosa, although only a portion of these molecules appear to have importance in pathogenesis through mobilization of iron. Interestingly, Leong et al. (1990) have demonstrated strong receptor specificity between an $86 \mathrm{kDa}$ OM receptor, the PupA gene product, in the potato-growth promoting pseudomonad Pseudomonas putida WCS358 and the ferric complex of its native siderophore, pseudobactin 358. Whilst not explaining why we observe interaction of the mAbs in this study with some $P$. aeruginosa strains but not others, these data contribute to the notion of strains having structurally different IROMPs depending on the structure of the pyoverdine-type siderophore they produce. An investigation of the chemical relatedness of the pyoverdines produced by these strains would be valuable to demonstrate this correlation.

From the immunogold results, it is not possible to conclude unequivocally whether the $85 \mathrm{kDa}$ IROMP is surface exposed. Only low-level gold binding was noted using the anti-85 kDa IROMP mAb C108 and the LPSdefective strain AK 1282. Moreover, it cannot be ruled out that this was attributable to binding to the lower molecular mass OM components with which it exhibited cross-reactivity in immunoblot studies. A larger study using more strains would be useful in this respect. The strong iodination of a protein migrating at $85 \mathrm{kDa}$ suggests surface exposure. This would be consistent with the postulated role of IROMPs as receptors for ironsiderophore complexes. However, it should be noted that this interpretation is based on the relative labelling of the $85 \mathrm{kDa}$ IROMP since many more proteins were weakly radiolabelled than are determined to be OM proteins by Sarkosyl solubilization studies. It has been reported that the lactoperoxidase method described by Lambert \& Booth (1982) was not specific and labelled other nonOM proteins (Sullivan \& Williams, 1982). From this study it would appear that the method based on Iodobeads falls into a similar category.

Possible reasons for the low-level binding of the anti$85 \mathrm{kDa}$ IROMP may be (1) reactivity against a primary rather than a conformational epitope, or (2) masking by
LPS. It is well recognized that antisera raised against a protein in a denatured form often react poorly or not at all with native protein (Benjamin et al., 1984; Gabay et al., 1985), the epitopes being buried within the threedimensional structure of the protein. The mAbs in this study were raised against IROMPs denatured by detergent solubilization. They reacted strongly with OM proteins separated by SDS-PAGE, but gave only low titres against whole cells in an ELISA assay $(1: 40$ to $1: 280)$ and low-level binding by immunogold electron microscopy. We believe that the low level of binding of the anti-85 kDa IROMP mAb in this study is attributable to masking of binding sites by LPS. Although the study was carried out using an LPS defective strain we found strong immunogold labelling with a mAb directed against a 'ladder-like' component of LPS on SDS-PAGE, typical of O-antigen. When an anti-core LPS/ lipid A mAb was used, the binding was lower than when the anti-O antigen $\mathrm{mAb}$ was used, even though it would be expected that the surface density of core LPS would be much greater than $\mathrm{O}$-antigen in the LPS-defective mutant. These data suggest some masking of LPS components, possibly including IROMPs, from interaction with immunoglobulins, by LPS O-antigen. Smaller molecules such as pyoverdine would not be inhibited from gaining access to these proteins. Mutharia \& Hancock (1983) reported a similar finding with mAbs directed against $P$. aeruginosa OMP $\mathrm{H}_{2}$. The $\mathrm{mAb}$ showed no fluorescence on intact, smooth cells, but was able to interact with a rough, LPS-deficient mutant. A similar phenomenon has been reported for the $74 \mathrm{kDa}$ ferric-aerobactin receptor in E. coli by Roberts et al. (1989). These workers also demonstrated that polyclonal antisera did not protect against infection with a smooth strain, suggesting that this receptor is not a good target for immunotherapy. Whilst a similar argument could be made against the IROMP described in this study, these IROMPs are dominant antigens in acute human infections (Ward et al., 1988), being immunologically recognized very early in the course of infection and prior to other OM components. It is therefore likely that they play a role in immune protection, but this is perhaps mediated or enhanced by LPS. The degree to which antibodies directed against the high molecular mass IROMPs might be involved in immune protection against $P$. aeruginosa infection is relatively unknown, but the ability of some of the mAbs to agglutinate cells may prime the complement cascade or facilitate opsonization. Our finding does, however, confirm an interaction with surface components.

The authors wish to thank Dr Peter Lambert and Dr Katherine Ward for helpful discussion and Barry Dowsett and Emily Elphich of the CAMR electron microscopy unit, Division of Pathology, for their assistance in producing the immunogold figures. 


\section{References}

ANwar, H., Brown, M. R. W., Day, A. \& Weller, P. H. (1984). Outer membrane antigens of mucoid Pseudomonas aeruginosa isolated directly from the sputum of a cystic fibrosis patient. FEMS Microbiology Letters 24, 235-239.

Benjamin, D. C., Berzofsky, J. A., East, I. J., Gurd, F. R. N. Hannum, C., Leach, S. J., Margoliash, E., Michael, J. G., Miller, A., Prager, E.M., Reichlin, M., Sercarz, E. E., SmithGill, S. J. \& Wilson, A. C. (1984). The antigenic structure of proteins: a reappraisal. Annual Review of Immunology 2, 67-101.

Bolin, C. A. \& JENSEN, A. E. (1987). Passive immunisation with antibodies against iron-regulated outer membrane proteins protects turkeys from Escherichia coli septicaemia. Infection and Immunity 55, 1239-1242.

Brown, M. R. W., ANWAR, H. \& LAMberT, P. A. (1984). Evidence that mucoid Pseudomonas aeruginosa in the cystic fibrosis lung grows under iron-restricted conditions. FEMS Microbiology Letters 21, 113-117.

Christoffersen, A. \& Cox, C. D. (1989). Pyoverdins from Pseudomonas aeruginosa which are effective in iron mobilization from transferrin. Abstracts for the Annual Meeting of the American Society for Microbiology D-151.

Cochrane, D. M. G., Brown, M. R. W., AnWar, H., Weller, P. H., LAM, K. \& Costerton, J. W. (1988). Antibody response to Pseudomonas aeruginosa surface protein antigens in a rat model of chronic lung infection. Journal of Medical Microbiology 27, 255-261.

CoRnelis, P., Moguilevsky, N., Jacques J. F. \& Masson, P. L. (1987). Study of the siderophores and receptors in different clinical isolates of Pseudomonas aeruginosa. Antibiotics and Chemotherapy 39, 290-306.

CoRnelis, P., Hohnadel, D. \& Meyer, J.-M. (1989). Evidence for different pyoverdine-mediated iron-uptake systems among Pseudomonas aeruginosa strains. Infection and Immunity 57, 3491-3497.

Filip, C., Fletcher, G., Wulff, J. L. \& Earhart, C. F. (1973). Solubilization of the cytoplasmic membrane of Escherichia coli by the ionic detergent sodium-lauryl sarcosinate. Journal of Bacteriology $115,717-722$

Gabay, J., Schenkman, S., Desaymard, C. \& Schwartz, M. (1985). Monoclonal antibodies and the structure of bacterial membrane proteins. In Monoclonal Antibodies Against Bacteria, pp. 249-282. Edited by A. J. L. de Macario \& C. de Macario. New York: Academic Press.

Gilleland, H. E., Parker, M. G., Matthews, J. M. \& Berg, R. D. (1984). Use of a purified outer membrane protein $F$ (porin) preparation of Pseudomonas aeruginosa as a protective vaccine in mice. Infection and Immunity 44, 49-54.

GRIFFITHS, E. (1987). The iron uptake systems of pathogenic bacteria. In Iron and Infection - Molecular, Physiological and Clinical Aspects, pp. 69-138. Edited by J. J. Bullen \& E. Griffiths. Chichester: John Wiley.

HACKSTADT, T. (1988). Steric hindrance of antibody binding to surface proteins of Coxiella burnetii by phase I lipopolysaccharide. Infection and Immunity 56, 802-807.

Hancock, R. E. W., Mutharia, L. M. \& Mouat, E. C. A. (1985) Immunotherapeutic potential of monoclonal antibodies against Pseudomonas aeruginosa protein F. European Journal of Clinical Microbiology 4, 224-227.

HECKELS, J. E. (1977). The surface properties of Neisseria gonorrhoeae: isolation of the major components of the outer membrane. Journal of General Microbiology 99, 333-341.

Holder, I. A. \& NaGlich, J. G. (1986) Experimental studies of the pathogenesis of infections due to Pseudomonas aeruginosa: immunization using divalent flagella preparations. Journal of Trauma $\mathbf{2 6}$ $118-122$.

JARRELL, K. \& KROPINSKI, A. M. (1981). Isolation and characterization of the bacteriophage specific for the lipopolysaccharide of rough derivatives of Pseudomonas aeruginosa strain PAO. Journal of Virology 38, 529-538.
Kohler, G. \& Milstern, C. (1976). Derivation of specific antibodyproducing tissue culture and tumour lines by cell fusion. European Journal of Immunology 6, 511-519.

LAEMMLI, U. K. (1970). Cleavage of structural proteins during the assembly of the head of bacteriophage T4. Nature, London 227, 680685.

LAMBerT, P. A. \& Booth, B. R. (1982). Exposure of outer membrane proteins on the surface of Pseudomonas aeruginosa PAO1 revealed by labelling with [125I]lactoperoxidase. FEMS Microbiology Letters 14, 43-45.

Leong, J., Bitter, W., Koster, M., Venturi, V., MarugG, J. D. \& WEISBEEK, P. J. (1990). Genetics of iron transport of plant growthpromoting Pseudomonas putida WCS358. (Abstract). International Symposium on Iron Transport, Storage and Metabolism II, Austin, TX, p. 23.

Matthews-Greer, J. M. \& Gilleland, H. E. (1987). Outer membrane protein $\mathbf{F}$ (porin) preparation of Pseudomonas aeruginosa as a protective vaccine against heterologous immunotype strains in a burned mouse model. Journal of Infectious Diseases 155, 1282-1291.

Montie, T. C., Craven, R. C. \& Holder, I. A. (1982). Flagellar preparations from Pseudomonas aeruginosa: isolation and characterization. Infection and Immunity 35, 281-288.

MUthaRia, L. M. \& HANCOCK, R. E. W. (1983). Surface localization of Pseudomonas aeruginosa outer membrane porin protein $\mathrm{F}$ by using monoclonal antibodies. Infection and Immunity 42, 1027-1033.

Mutharia, L. M., Nicas, T. I. \& Hancock, R. E. W. (1982). Outer membrane proteins of Pseudomonas aeruginosa serotype strains. Journal of Infectious Diseases 146, 770-779.

NeILANDS, J. B. (1982). Microbial envelope proteins related to iron. Annual Review of Microbiology 36, 285-309.

Roberts, M., WoOldridge, K. G., Gavine, H., Iravati Kuswandi, S. \& WILliams, P. H. (1989). Inhibition of biological activities of the aerobactin receptor protein in rough strains of Escherichia coli by polyclonal antiserum raised against native protein. Journal of General Microbiology 135, 2387-2398.

Smith. H. (1990). Pathogenicity and the microbe in vivo. Journal of General Microbiology 136, 377-383.

Sokol, P. A. \& Woods, D. E. (1983). Demonstration of an ironsiderophore-binding protein in the outer membrane of Pseudomonas aeruginosa. Infection and Immunity 40, 665-669.

SokoL, P. A. \& Woods, D. E. (1986a). Characterization of antibody to the ferripyochelin binding protein of Pseudomonas aeruginosa. Infection and Immunity 51, 896-900.

SoKol, P. A. \& Woods, D. E. $(1986 b)$. Monoclonal antibodies to Pseudomonas aeruginosa ferripyochelin binding protein. Infection and Immunity 53, 621-627.

Sullivan, K. H. \& Williams, R. P. (1982). Use of Iodo-Gen and iodine-125 to label the outer membranes of Neisseria gonorrhoeae. Analytical Biochemistry 34, 254-258.

Towbin, H., Staehelin, T. \& GoRdon, J. (1979). Electrophoretic transfer of proteins from polyacrylamide gels to nitrocellulose sheets: procedure and some applications. Proceedings of the National Academy of Sciences of the United States of America 76, 4350-4354.

TSAI, G. M. \& FrasCH, C. (1982). A sensitive silver stain for detecting lipopolysaccharides in polyacrylamide gels. Analytical Biochemistry 119, $115-119$

Ward, K. H., AnWar, H., Brown, M. R. W., Wale, J. \& Gowar, J. (1988). Antibody response to outer membrane antigens of Pseudomonas aeruginosa in human burn wound infection. Journal of Medical Microbiology 27, 179-190.

WESTPHAL, O. \& JANN, K. (1965). Bacterial lipopolysaccharides: extraction with phenol-water and further applications of the procedure. Methods in Carbohydrate Chemistry 5, 83-91. 